\title{
A P-Simulator with Carriers of Cellular Respiration and Mitochondrial Oxidative Metabolism
}

\author{
Lamia Hassaan Ahmed, Amr Ahmed Badr, and Ibrahim Farag Abd El-Rahaman
}

\begin{abstract}
Aerobic respiration is the process of oxidizing food molecules to carbon dioxide and water in the presence of oxygen to produce energy. The functions done by the cell and its mitochondrion to produce energy can be simulated by computer programs. One approach is a membrane system which is also called $P$ system. $P$ systems are usually accompanied by transition rules that represent cellular chemical reactions and carrier rules that represent the transportation of cellular molecules without changing them. The proposed simulator is a Java simulator that implements $P$ systems with transition rules and carriers in order to simulate cellular energy production. The results of the system meet the values of cellular metabolism and correctly vary according to the inputs.
\end{abstract}

Index Terms-Natural Computing, P Simulator, P Systems, P Systems with carriers.

\section{INTRODUCTION}

P systems are computational models that are based on the idea of cellular membrane structure and functions; they were presented by Gh. Paun in [3]. It is a branch of natural computing whose initial goal is to abstract computing models from the structure and the functioning of living cells [4]. The chemical reactions controlling the change of molecules are represented by evolution rules -also called multiset rewriting rules $[3,5]-$ and the chemical reactions controlling transportation of molecules without changing them are represented by communication rules [3,5]. Communication rules can either be symport/antiport rules or rules with carriers [2] which will be used in the proposed simulator. $\mathrm{P}$ systems employ these rules in order to transform from a computational status to another.

A simple transition $P$ system is constructed of the form [5]:

where:

$$
\mathrm{II}=\left(\mathrm{O}, \mathrm{C}, \mu, \mathrm{w}_{1}, \mathrm{w}_{2}, \ldots, \mathrm{w}_{\mathrm{n}}, \mathrm{R}_{1}, \mathrm{R}_{2}, \ldots, \mathrm{R}_{\mathrm{n}}, \mathrm{i}_{\mathrm{o}}\right)
$$

O: The alphabet of objects, i.e. cellular molecules.

$\mathrm{C}$ : The alphabet of catalysts, if any.

$\mu$ : The membrane structure. It consists of $n$ membranes labeled with $1,2,3, . ., \mathrm{n}$.

$\mathrm{w}_{1}, \mathrm{w}_{2}, \mathrm{w}_{\mathrm{n}}$ : The strings over $\mathrm{O} \cup \mathrm{C}$, representing the multisets of objects initially present in all regions of the

Manuscript received October 24, 2010; revised January 4, 2011.

Lamiaa Hassaan Ahmed is a PhD student at Cairo University, Faculty of Computers and Information, Computer Science Department. Phone: +20185533313 E-mail: lamia_work@yahoo.com).

Amr Badr is with Cairo University, Faculty of Computers and Information, Computer Science Department. (e-mail: a.badr.fci@gmail.com).

Ibrahim Farag is with Cairo University, Faculty of Computers and Information, Computer Science Department. (e-mail: i.farag@fci-cu.edu.eg). system membrane structure [5].

$\mathrm{R}_{1}, \mathrm{R}_{2}, \mathrm{R}_{\mathrm{n}}$ : The set of evolution rules associated with the regions of the system.

$\mathrm{i}_{\mathrm{o}}$ : The output region. It will take one of the labels $1,2, \ldots n$. Objects are assigned to rules by choosing rules and objects non-deterministically. Also, the chosen multiset of rules should be applicable to the chosen multiset of objects currently available. When no other rules can be applied on the current multiset of objects, the multiset of rules is said to be maximal. Different rules can be applied on different objects in parallel. We can conclude that $\mathrm{P}$ systems run in a maximally parallel non-determinitic manner [2].

\section{A. Aerobic respiration:}

Aerobic respiration is a process of energy production from food in the presence of oxygen [1]. The produced energy is stored in adenosine triphosphate i.e. ATP molecules. The cell has its plasma membrane and the mitochondrion has an inner and an outer membrane. The composition and organization of these membranes are the keys to the bioenergetic activities of the mitochondrion [1]. Also, the inner membrane of the mitochondrion contains a variety of transport systems as well as being the location of most of the machinery required for the synthesis of ATP [1].

In this paper, $\mathrm{P}$ systems are used for simulating the basic metabolic functions of the cellular mitochondria including the transition and transportation of cellular molecules. Section II of this paper shows a brief history of simulators of cellular respiration using $\mathrm{P}$ systems, section III defines the problem of cellular energy production and the mitochondrial chemical equations, section IV explains the structure and functions of the proposed simulator and finally section $\mathrm{V}$ which shows the results of the simulator.

\section{LITERATURE SURVEY}

The cellular respiratory system of the bacterium Escherichia Coli was presented using logic gates in [6]. There are other published metabolic simulators like MetaPlab which is produced by the Italian university Verdona [7]. It is a deterministic $\mathrm{P}$ system developed to model dynamics of biological phenomena related to metabolism. It added a new plugin based framework for processing metabolic P systems. Also, there is a simulator for Biological Processes produced by University of Sheffield, UK in 2006[8]. It simulates the evolution of Multi-compartmental Gillespie algorithm over a hierarchy of compartment structures. Another simulator, CytoSim simulator which is produced by the Microsoft Research - University of Trento Centre for Computational and Systems Biology, Trento, Italy. This simulator is a 
stochastic simulator of biochemical processes in hierarchical compartments. The compartments may be isolated or may communicate via peripheral and integral membrane proteins [9]. There are many other simulators that are concerned with the implementation of $\mathrm{P}$ systems on other research fields like neural networks, dynamical probabilistic $\mathrm{P}$ systems and membrane approximation algorithms [10].

\section{PROBLEM DEFINITION}

A. - The Aerobic Respiratory System and the Mitochondrion

A living cell has a plasma membrane (cell wall) which holds all the components of the cell like cytoplasm, the nucleus, the mitochondria, the ribosome, and different molecules like potassium, hydrogen, water, etc. See fig. 1 [11].

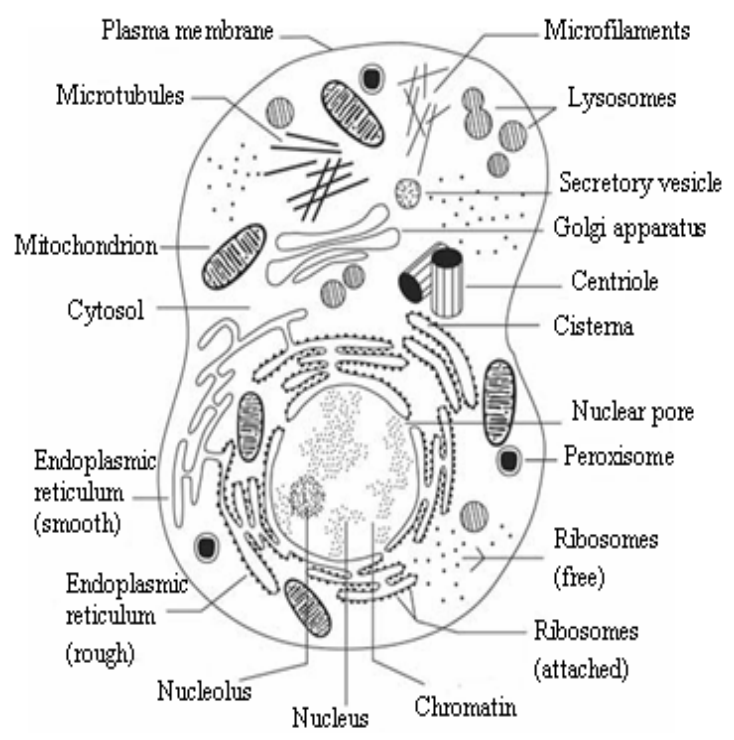

Fig. 1: Cell structure

An aerobic cell is the one which depends on oxygen to extract energy. Energy extraction takes place in a specified organelle, the mitochondrion [1]. A mitochondrion, as shown in fig. 2 [12], consists of two membranes, the outer membrane and the inner membrane. An intermembrane space is the area between the two membranes. The matrix is the compartment within the inner membrane [1].

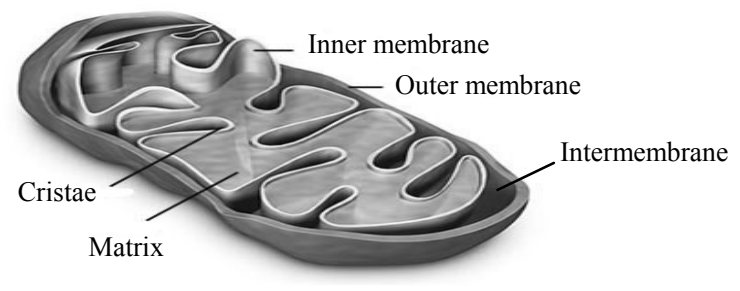

Fig. 2: The mitochondrial structure

The architecture of the mitochondrial inner membrane and its fluidity facilitate the interactions of molecules required to produce energy in the form of ATP molecules [1].

\section{B. Oxidative Metabolism and the Mitochondrion}

Oxidative metabolism is the set of the metabolic reactions and processes that take place in organisms' cells to convert biochemical energy from nutrients into adenosine triphosphate (ATP), and then release waste products [1]. Mitochondrion is the supplier of ATPs which are considered as the fuel of the cell [1]. Table IV clarifies the chemical names of the cellular molecules used within this paper.

Steps of glucose and fatty acid oxidative metabolism [1], [13]-[15]:

1) Glycolysis

It starts with one molecule of glucose. It happens in the cytoplasm of the cell. It produces two molecules of pyruvate, ATP and reduces NAD to NADH.

The glycolysis equation is [1]:

$$
\begin{aligned}
& \text { Glucose }+2 \mathrm{NAD}+2 \mathrm{ADP}+2 \mathrm{P} \rightarrow \\
& \text { 2Pyruvate }+2 \mathrm{ATP}+2 \mathrm{NADH}+2 \mathrm{H}^{+}+\mathrm{H}_{2} \mathrm{O}
\end{aligned}
$$

2) Oxidative decarboxylation of pyruvate

Pyruvate enters the inner mitochondrial membrane, it is transformed into acetyl-CoA, $\mathrm{CO}_{2}$ and NAD is reduced to NADH [1]. Notice that this equation transforms only one molecule of pyruvate [14].

$$
\begin{aligned}
& \text { Pyruvate }+\mathrm{NAD}+\mathrm{CoA} \rightarrow \\
& \text { Acetyl }-\mathrm{Co} A+\mathrm{NADH}+\mathrm{H}^{+}+\mathrm{CO}_{2}
\end{aligned}
$$

\section{3) Fatty acid activation}

At the same time of glycolysis, fatty acid molecules may exist in the cytoplasm of the cell. They go through the fatty acid activation process consuming two ATP molecules. This process has the equation [15]

$$
\begin{aligned}
& \text { Fatty acid }+2 A T P+\operatorname{CoA} \rightarrow \\
& \text { Acyl-CoA }+P P+A M P
\end{aligned}
$$

4) Acyl-CoA transportation

The Acyl-CoA is transported to the outer membrane of the mitochondrion where the following reaction takes place [15]

$$
\text { Acyl-CoA }+ \text { Carnitine } \rightarrow \text { Acylcarnitine }
$$

\section{5) Acylcarnitine transportation}

Acylcarnitine is then transported into the inner mitochondrial membrane, where the following reaction takes place [15]

$$
\begin{aligned}
\text { Acylcarnitine }+\operatorname{CoA} \underset{\text { Acyl-CoA }+ \text { Carnitine }}{\rightarrow} &
\end{aligned}
$$

\section{6) Acyl-CoA transformation}

Acyl-CoA is then transformed into Acetyl-CoA as follows [15]

$$
\begin{array}{r}
\text { Acyl-CoA }+7 \mathrm{FAD}+7 \mathrm{NAD}+7 \mathrm{CoA}+7 \mathrm{H}_{2} \mathrm{O} \rightarrow \\
8 \text { Acetyl-CoA }+7 \mathrm{FADH}_{2}+7 \mathrm{NADH}+7 \mathrm{H}^{+}
\end{array}
$$

\section{7) Citric Acid Cycle (Kerb's Cycle)}

$$
\begin{gathered}
\text { Acetyl-CoA }+\mathrm{FAD}+3 \mathrm{NAD}+\mathrm{GDP}+\mathrm{P}+2 \mathrm{H}_{2} \mathrm{O} \rightarrow \\
3 \mathrm{NADH}+\mathrm{FADH}_{2}+\mathrm{GTP}+\mathrm{CoA}+3 \mathrm{H}^{+}+2 \mathrm{CO}_{2}
\end{gathered}
$$

The acetyl-CoA molecules coming from glucose in steps 1 and 2 and from fatty acid in steps 3 to 5 enter the citric acid cycle (Kreb's cycle) inside the mitochondrial matrix, and get 
oxidized to $\mathrm{CO}_{2}, \mathrm{NAD}$ is reduced to $\mathrm{NADH}$ and FAD is reduced to $\mathrm{FADH}_{2}[1],[14]$.

Fig. 3 [1],[13] shows the basic metabolic functions of the mitochondrion. Notice that, $\mathrm{NADH}$ and $\mathrm{FADH}_{2}$ are produced by glycolysis and Kerb's cycle. Steps 9 and 10 are done in order to utilize NADH and $\mathrm{FADH}_{2}$ to produce ATPs[1].

\section{8) Transformation of GTP}

GTP is transformed again into GDP by reacting with ADP to produce ATP

$$
\mathrm{GTP}+\mathrm{ADP} \rightarrow \mathrm{GDP}+\mathrm{ATP}
$$

\section{9) The Electron Transport Chain}

An electron transport chain consists of a series of specific electron carriers which exist in the inner mitochondrial membrane [1]. The function of the electron transport chain is coupling a chemical reaction between an electron donor (such as $\mathrm{NADH}, \mathrm{FADH}_{2}$ ) and an electron acceptor (such as $\mathrm{O}_{2}$ ) to the transfer of $\mathrm{H}_{+}$ions across a membrane, through a set of mediating biochemical reactions.

$\mathrm{NADH}$ and $\mathrm{FADH}_{2}$ are high energy electron carriers that can be used by the electron transport chain to create further ATPs. The electrons are passed from a carrier to another in the electron transport chain till the final acceptor which is $\mathrm{O}_{2}$. $\mathrm{O}_{2}$ is then reduced to water [1]. The energy released is used to set up a proton gradient of $\mathrm{H}^{+}$across the mitochondrial inner membrane to the mitochondrial intermembrane space. The next and final step will show how these protons are used to produce more ATPs. In addition to NADH and $\mathrm{FADH}_{2}$, there are other electron carries within the electron transport chain, they are cytochromes ( $a, a_{3}, b, c$ and $\left.c_{1}\right)$, ubiquinone(UQ) and iron-sulfur proteins $(\mathrm{FeS})[1]$. Some of these carriers are part of four distinct, asymmetric, membrane spanning complexes identified as complexes I, II, III, and IV [1]. Fig. 4 [1] illustrates the detailed electron transport chain. Notice that cytochrome-c and ubiquinone are not part of any of the four complexes [1].

- Complex I:

It catalyzes the transfer of two electrons from NADH to ubiquinone. Ubiquinone becomes ubiquinol. This passage of a pair of electrons through complex $\mathrm{I}$ is thought to be accompanied by a movement of four protons into the intermembrane space [1].

$$
N A D H+4 \mathrm{H}^{+}+\mathrm{UQ} \stackrel{\text { ComplexI }}{\longrightarrow} \mathrm{NAD}^{+}+\mathrm{UQH}_{2}+4 \mathrm{H}^{+}
$$

- Complex II:

It catalyzes the transfer of two electrons from $\mathrm{FADH}_{2}$ to ubiquinone but it is not accompanied by proton translocation [1].

$$
\mathrm{FADH}_{2}+\mathrm{UQ} \stackrel{\text { Complex II }}{\longrightarrow} \mathrm{FAD}^{+}+\mathrm{UQH}_{2}
$$

- Complex III:

It catalyzes the transfer of two electrons from ubiquinol to cytochrome c. Four protons are transferred into the intermembrane space for every pair of electrons pass through complex III [1]. Two of these protons come from the ubiquinol molecule and the other two protons are removed from the mitochondrial matrix [1].

$$
\mathrm{UQH}_{2}+2 \mathrm{H}^{+} \stackrel{\text { ComplexIII }}{\longrightarrow} U Q+4 H^{+}+2 e^{-}
$$

According to [1],[13], complex III transports electrons to complex IV using the carrier cytochrome-c through the intermembrane space as cytochrome-c is thought to be mobile [1]., see fig. 4 [1]. Notice that ${ }^{C y t}{ }_{c}{ }^{3+}$ is reduced to $\mathrm{Cyt}_{c}{ }^{2+}$ by accepting electrons. This is illustrated in the following equation:

$$
\mathrm{Cyt}_{c}{ }^{3+}+2 e^{-} \rightarrow \mathrm{Cyt}_{c}{ }^{2+}
$$

- Complex IV:

The final step of the electron transport chain is the transfer of electrons from reduced cytochrome $\mathrm{c}$ to oxygen.

$$
2 \mathrm{Cyt}_{c}{ }^{2+}+\frac{1}{2} \mathrm{O}_{2}+2 \mathrm{H}^{+} \stackrel{\text { ComlexIV }}{\longrightarrow} \mathrm{H}_{2} \mathrm{O}+2 \mathrm{Cyt}_{c}{ }^{3+}+2 \mathrm{H}^{+}
$$

A schematic diagram of the components of the electron transport chain within the inner mitochondrial membrane is shown in fig. 4 [1].

10) Movement of protons back into the mitochondrial membrane and ATP formation

This is the final step of the mitochondrial oxidative metabolism. Protons now exist in the intermembrane space. They flow back across the inner mitochondrial membrane through the ATP synthesizing enzyme. This controlled movement of protons provides the energy required to phosphorylate ADP to ATP [1]. ATP synthase is sometimes described as Complex V of the electron transport chain. The equation of ATP formation at this stage will be [1]:

$$
A D P+P \rightarrow A T P+\mathrm{H}_{2} \mathrm{O}
$$

\section{Total number of ATPS}

How many ATPs should the oxidative metabolism produce given one molecule of glucose and one molecule of fatty acid? Each pair of electrons transferred from NADH to oxygen via the electron transport chain releases energy enough to formulate three molecules of ATP, and each pair of electrons transferred from $\mathrm{FADH}_{2}$ to oxygen via the electron transport chain releases energy enough to formulate two

\begin{tabular}{|c|c|}
\hline Step & $\begin{array}{l}\text { Number } \\
\text { of ATPs }\end{array}$ \\
\hline 1- Glycolysis: 2NADH $\times 3+2$ ATPs & +8 \\
\hline $\begin{array}{l}\text { 2- Pyruvate conversion to Acetyl-CoA: } \\
2 \mathrm{NADH} \times 3\end{array}$ & +6 \\
\hline 3- Fatty acid activation: & -2 \\
\hline $\begin{array}{l}\text { 4- Kerb's cycle "from pyruvate } \\
\text { conversion to Acetyl-CoA" } \\
6 \mathrm{NADH} \times 3+2 \mathrm{FADH}_{2} \times 2+2 \mathrm{GTP}\end{array}$ & +24 \\
\hline $\begin{array}{l}\text { 5- Acyl-CoA conversion to Acetyl-CoA: } \\
\text { 7NADH } \times 3+7 \mathrm{FADH}_{2} \times 2\end{array}$ & +35 \\
\hline $\begin{array}{l}\text { 6- Kerb's cycle "from Acyl-CoA } \\
\text { conversion to Acetyl-CoA" } \\
24 \mathrm{NADH} \times 3+8 \mathrm{FADH}_{2} \times 2+8 \mathrm{GTP}\end{array}$ & +96 \\
\hline Total & +167 \\
\hline
\end{tabular}
molecules of ATP [1]. GTP is added as one ATP molecule. So, when we add up all the ATPs formed by the complete metabolism of one molecule of glucose and one molecule of fatty acid, it will be 167 ATP molecules. This is illustrated in table I:

TABLE I: TOTAL NUMBER OF ATPS 


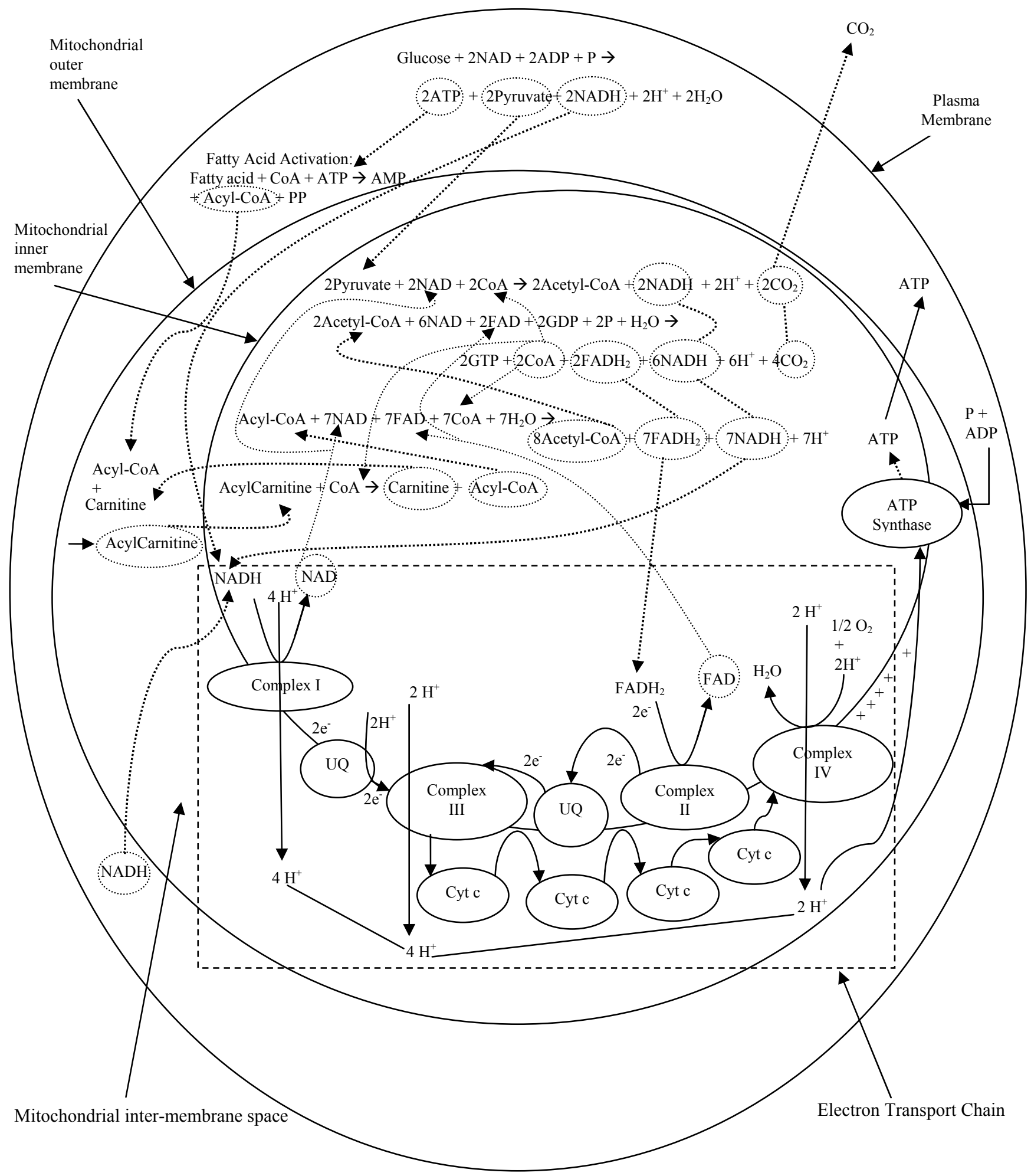

Fig. 3: The mitochondrial energy production cycle 


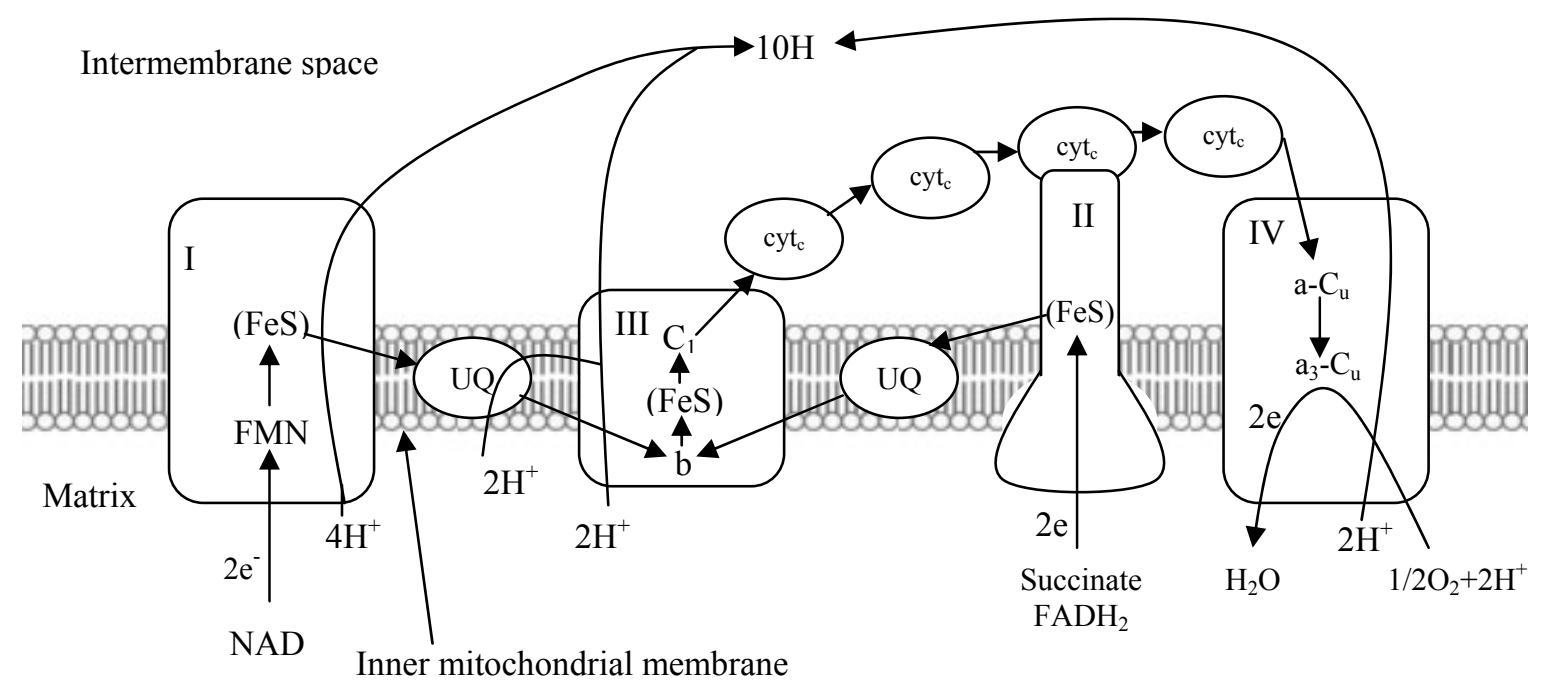

Fig. 4: Components of the electron transport chain

Notice that the above calculation of the total number of ATPs only includes NADH and $\mathrm{FADH}_{2}$. Given enough energy produced by the proton movement back across the inner mitochondrial membrane and enough number of $\mathrm{H}+, \mathrm{P}$ and ADP molecules, further ATPs can be produced by ATP synthase. See equation 14 in section III and fig. 4.

\section{The Proposed SimUlator}

\section{A. The construct of the P system}

This paper is proposing a system that simulates the aerobic cellular respiration and energy production by mitochondrial oxidative metabolism. The simulator is based on the concept of membrane systems -P systems- with evolution rules (transition P system) [2] and communication rules (P system with carriers) [2]. The package JDK1.3 or later should be installed before running this simulator because it is implemented in Java,. The P system form of the proposed simulator will be:

Where:

$$
\mathrm{II}_{\mathrm{sim}}=\left(\mathbf{O}, \mathbf{C}, \mu, \mathbf{w}_{1}, \mathbf{w}_{2}, \mathbf{w}_{3}, \mathbf{R}_{\mathrm{e} 1}, \mathbf{R}_{\mathrm{e} 2}, \mathbf{R}_{\mathrm{e} 3}, \mathbf{R c}_{2}, \mathbf{R c}_{3}, \mathbf{i}_{\mathbf{0}}\right)
$$

- O: The alphabet of objects.

$\mathrm{O}=$ \{Glucose, NAD, ADP, P, Fatty-Acid, CoA, ATP, Acyl-CoA, $\mathrm{H}_{2} \mathrm{O}, \mathrm{FAD}$, GDP, pyruvate, Carnitine, Acyl-CoA, Acylcarnitine, Acetyl-CoA, $\mathrm{H}^{+}, \mathrm{GTP}, 2 e^{-}, \mathrm{O}_{2}$ \}

- C: The alphabet of carriers [2].

$$
\mathrm{C}=\left\{\mathrm{NADH}, \mathrm{FADH}_{2}, \mathrm{UQ}, \mathrm{UQH}_{2}, \mathrm{Cyt}_{c}^{+3}, \mathrm{Cyt}_{c}^{+2}\right\} \text {. }
$$

$-\mu$ : The membrane structure [2]. The plasma membrane will take label 1, the outer mitochondrial membrane will take label 2 and the inner mitochondrial membrane will take label 3 . The structure is $\left.\mu=\left[\begin{array}{lll}1 & {\left[\begin{array}{ll}2 & {[}\end{array}\right]_{3}}\end{array}\right]_{2}\right]_{1}$. This means that membrane 3 is inside membrane 2 which is inside membrane 1 .

$-\mathrm{w}_{1}, \mathrm{w}_{2}, \mathrm{w}_{3}$ : The strings over $\mathrm{O} \cup \mathrm{C}$ [2], representing the multisets of objects and carriers initially present region 1,2 and 3 respectively. These strings will be formed by the user's input and the output of some rules.

$\mathrm{w}_{1}=\left\{\right.$ \#glucose, \#fatty_acid, \#ADP, \# $\mathrm{H}^{+}$, \# NADH, \#pyruvate, \# NAD, \#CoA, \#P, \# $\mathrm{H}_{2} \mathrm{O}$, \#ATP, \# Acyl-CoA $\mathrm{w}_{2}=\left\{\#\right.$ acyl_CoA, \#carnitine, \#acyl_carnitine, Cyt ${ }_{c}{ }^{2+}$, $\left.2 e^{-}, \mathrm{Cyt}_{c}^{3+}, \mathrm{H}^{+}\right\}$

$\mathrm{w}_{3}=\left\{\#\right.$ pyruvate, \#NAD, \#CoA, \#P, \# $\mathrm{H}_{2} \mathrm{O}, \# \mathrm{FAD}, \# \mathrm{GDP}$, \# acetyl_CoA, \#acyl_CoA, \#acyl_carnitine, \#carnitine, \# $\mathrm{FADH}_{2}$, \#NADDH, \# $\mathrm{H}^{+}, \mathrm{GTP}, \mathrm{UQ}$, $\left.\mathrm{UQH}_{2}, 2 \mathrm{e}^{-}, \mathrm{O}_{2}, \mathrm{ADP}, \mathrm{ATP}\right\}$

$-\mathrm{R}_{\mathrm{e} 1}, \mathrm{R}_{\mathrm{e} 2}, \mathrm{R}_{\mathrm{e} 3}$ : The set of evolution rules associated with the three regions of the system. They are in the form $u \rightarrow v$ where $u$ is a string over $\mathrm{O}$ and $v$ is a string over $\mathrm{O}_{\operatorname{tar}}$, where $\mathrm{O}_{\mathrm{tar}}=\mathrm{O}$ X TAR [2] for $\mathrm{TAR}=\{1,2,3\}$. This means that every reaction indicates the output objects and the region to which the output objects will be moved. When there is no target indicator i.e. 1 or 2 or 3 , this means that the outcome of the applied reaction will remain in the current region. It is important to notice that $\mathrm{PP}$, AMP and $\mathrm{CO}_{2}$ are neglected as there is no further use of them. Also, complexes I, II, III, IV and ATP synthase are assumed to be already existing in the mitochondrial inner membrane.

$$
\begin{aligned}
& -\mathrm{R}_{\mathrm{el}}=\left\{r_{l}=\text { Glucose }+2 N A D+2 A D P+2 P \rightarrow\right. \\
& (2 \text { Pyruvate }, 3)+2 A T P+(2 N A D H, 3)+\left(2 H^{+}, 3\right)+ \\
& \left(2 \mathrm{H}_{2} \mathrm{O}, 3\right) \text {, } \\
& r_{2}=\text { Fatty acid }+2 A T P+C o A \rightarrow\left(A c y l \_C o A, 2\right), \\
& r_{3}=N A D \rightarrow(N A D, 3) \text {, } \\
& r_{4}=\mathrm{CoA} \rightarrow(\mathrm{CoA}, 3) \text {, } \\
& r_{5}=P \rightarrow(P, 3) \text {, } \\
& \left.r_{6}=A D P \rightarrow(A D P, 3)\right\} \\
& \left.\mathrm{R}_{\mathrm{e} 2}=\left\{r_{7}=\text { Acyl_CoA }+ \text { Carnitine } \rightarrow \text { (Acylcarnitine, } 3\right)\right\} \\
& \mathrm{R}_{\mathrm{e} 3}=\left\{r_{8}=\text { Pyruvate }+N A D+C o A \rightarrow\right. \\
& \text { Acetyl_CoA }+\mathrm{NADH}+\mathrm{H}^{+} \text {, } \\
& r_{9}=\text { Acetyl_CoA }+F A D+3 N A D+G D P+P+2 \mathrm{H}_{2} \mathrm{O} \\
& \rightarrow 3 \mathrm{NADH}+\mathrm{FADH}_{2}+\mathrm{GTP}+\mathrm{CoA}+3 \mathrm{H}^{+} \text {, } \\
& r_{10}=A c y l \_C o A+7 F A D+7 N A D+7 \mathrm{CoA}+7 \mathrm{H}_{2} \mathrm{O} \rightarrow \\
& 8 \text { Acetyl } \mathrm{CoA}+7 \mathrm{FADH}_{2}+7 \mathrm{NADH}+7 \mathrm{H}^{+} \text {, } \\
& r_{11}=\text { Acylcarnitine }+\mathrm{CoA} \rightarrow \text { Acyl_CoA }+ \text { (Carnitine,2), } \\
& \left.r_{12}=G T P+A D P \rightarrow A T P+G D P\right\}
\end{aligned}
$$
region surrounded with the membranes labeled 2 and 3 respectively. 


$$
\begin{aligned}
& -\mathrm{R}_{\mathrm{c} 2}=\left\{r_{13}=C y t_{c}{ }^{3+}+2 e^{-} \rightarrow C y t_{c}{ }^{2+}\right. \text {, } \\
& \mathrm{r}_{14}=\mathrm{Cyt}_{c}{ }^{2+} \rightarrow \mathrm{Cyt}_{c}{ }^{3+}+\left(2 e^{-}, 3\right), \\
& \left.r_{15}=\left(H^{+}, 3\right)\right\} \\
& -\mathrm{R}_{\mathrm{c} 3}=\{ \\
& \mathrm{r}_{16}=N A D H+4 \mathrm{H}^{+}+\mathrm{UQ}-\underline{\text { Complex } \mathrm{I}} \rightarrow \\
& \mathrm{NAD}+\mathrm{UQH}_{2}+\left(4 \mathrm{H}^{+}, 2\right)+3 \text { energy _units , } \\
& r_{17}=\mathrm{FADH}+\mathrm{UQ} \stackrel{\text { Completl }}{\longrightarrow} F A D^{+}+U Q H_{2}+2 \text { energy_units, } \\
& r_{18}={ }_{U Q H} H_{2}+2 H^{+}-\underline{\text { ComplexllI }} \rightarrow U Q+\left(4 H^{+}, 2\right)+\left(2 e^{-}, 2\right), \\
& r_{19}=4 e^{-}+\mathrm{O}_{2}+4 \mathrm{H}^{+} \longrightarrow \text { Complexl } \longrightarrow 2 \mathrm{H}_{2} \mathrm{O}+\left(4 \mathrm{H}^{+}, 2\right) \text {, } \\
& \left.r_{20}=A D P+P+H^{+} \stackrel{\text { ATP_Synthase }}{\longrightarrow}(A T P, 1)+H_{2} \mathrm{O}\right\}
\end{aligned}
$$

- $\mathrm{i}_{\mathrm{o}}$ : The output region. $\mathrm{i}_{1}$ is the output membrane of the system.

The proposed simulator is implemented using Java programming language, which is well known of threads. Threads are used in order to preserve the condition of applying rules in a maximally parallel manner. The condition of applying rules in a non-deterministic manner is preserved by randomly choosing rules and objects within every region. The input to the system is the number of glucose molecules, fatty acid molecules, ADP, NAD, P, CoA, ATP (for fatty acid activation), Carnitine, FAD, $\mathrm{H}_{2} \mathrm{O}, \mathrm{H}^{+}, \mathrm{O}_{2}$, GDP, UQ and $\mathrm{Cyt}_{c}{ }^{3+}$. There is an option to choose whether we want to apply glucose metabolism or fatty acid metabolism or both. The output of the system is the total number of ATPs after the system has applied the complete steps of the chosen type of metabolism (glucose or fatty acid or both) and the electron transport chain followed by ATP synthase reaction. Because of the non-deterministic maximally parallel condition, the output also shows the order in which rules are applied. It is used to evaluate the correctness of the simulator.

\section{B. A simple diagram of the simulator}

Fig. 5 shows a simple diagram of the main classes and methods of the proposed simulator. There are three main classes Membrane1, Membrane2, Membrane3 which represent the plasma membrane, the mitochondrial outer membrane and the mitochondrial inner membrane respectively. Each class of the membrane classes contains the number of each molecule used in this membrane. The method runApp is used to get the input i.e. number of molecules from the user via the user interface and it passes these input values to each membrane object. Rules are built in other methods like glycolysis, fat_activation, produce_AcylCar, etc. These methods are run in multiple threads in order to preserve the condition of parallel random execution of rules.

\section{EXPERIMENTS AND RESULTS}

The output of the system is- as mentioned before -the total number of ATPs generated by either glucose metabolism or fatty acid metabolism or both. The results depend on the input to the system and the order in which rules are applied which changes every time we run the system because of the non-determinism of applying rules.

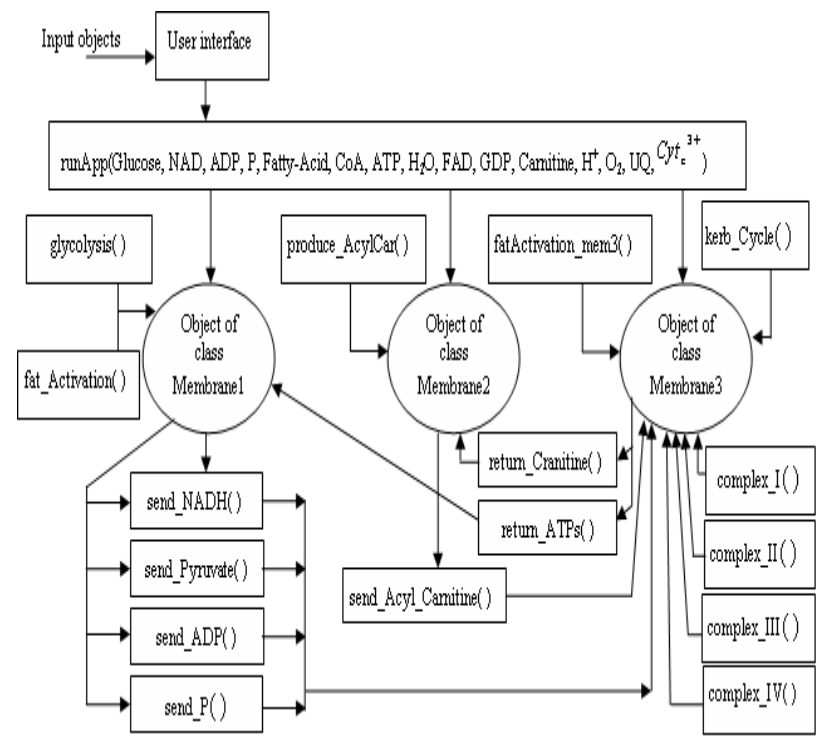

Fig. 5: A simple diagram of the main classes and methods of the simulator

\section{A. An Example}

The following input values in table II represent the minimum number of molecules needed to apply complete metabolism on one molecule of glucose and one molecule of fatty acid. Also, these values are enough to apply the rules of the electron transport chain.

TABLE II: AN EXAMPLE OF SYSTEM INPUTS

\begin{tabular}{|cccc|}
\hline Molecule name & $\begin{array}{c}\text { The least } \\
\text { required } \\
\text { number }\end{array}$ & $\begin{array}{c}\text { Molecule } \\
\text { name }\end{array}$ & $\begin{array}{c}\text { he least required } \\
\text { number }\end{array}$ \\
\hline Glucose & 1 & $\mathrm{ADP}$ & 582 \\
\hline Fatty Acid & 1 & $\mathrm{ATP}$ & 0 \\
\hline NAD & 41 & $\mathrm{FAD}$ & 17 \\
\hline CoA & 11 & $\mathrm{H}^{+}$ & 413 \\
\hline Carnitine & 1 & $\mathrm{P}$ & 582 \\
\hline $\mathbf{H}_{2} \mathbf{O}$ & 25 & $\mathrm{Cyt}_{c}{ }^{3+}$ & 58 \\
\hline (in membrane 3) & 29 & $\mathrm{UQ}$ & 58 \\
\hline $\mathbf{O}_{2}$ & 9 & \\
\hline GDP &
\end{tabular}

Keeping in mind that $\mathrm{P}$ systems preserve the property of using rules and objects in a maximally parallel non-deterministic manner, table III represents a possible evolution of the results and the use of rewriting rules within the system cycles.

As NADH and $\mathrm{FADH}_{2}$ are electron carriers, energy is produced when they pass electrons to the next carrier in the electron transport chain. NADH produces energy enough to create 3 ATPs and $\mathrm{FADH}_{2}$ produces energy enough to create 2 ATPs as they pass electrons to oxygen through the electron transport chain [1]. That is the reason why there is a column belongs to membrane three called "energy units". Also, we notice that there are some molecules that are not included in table III like $\mathrm{Co}_{2}$, AMP and PP. These molecules are not used as input molecules in other rules, that is why they are neglected. 
TABLE III: PHASES OF EXPERIMENT 1

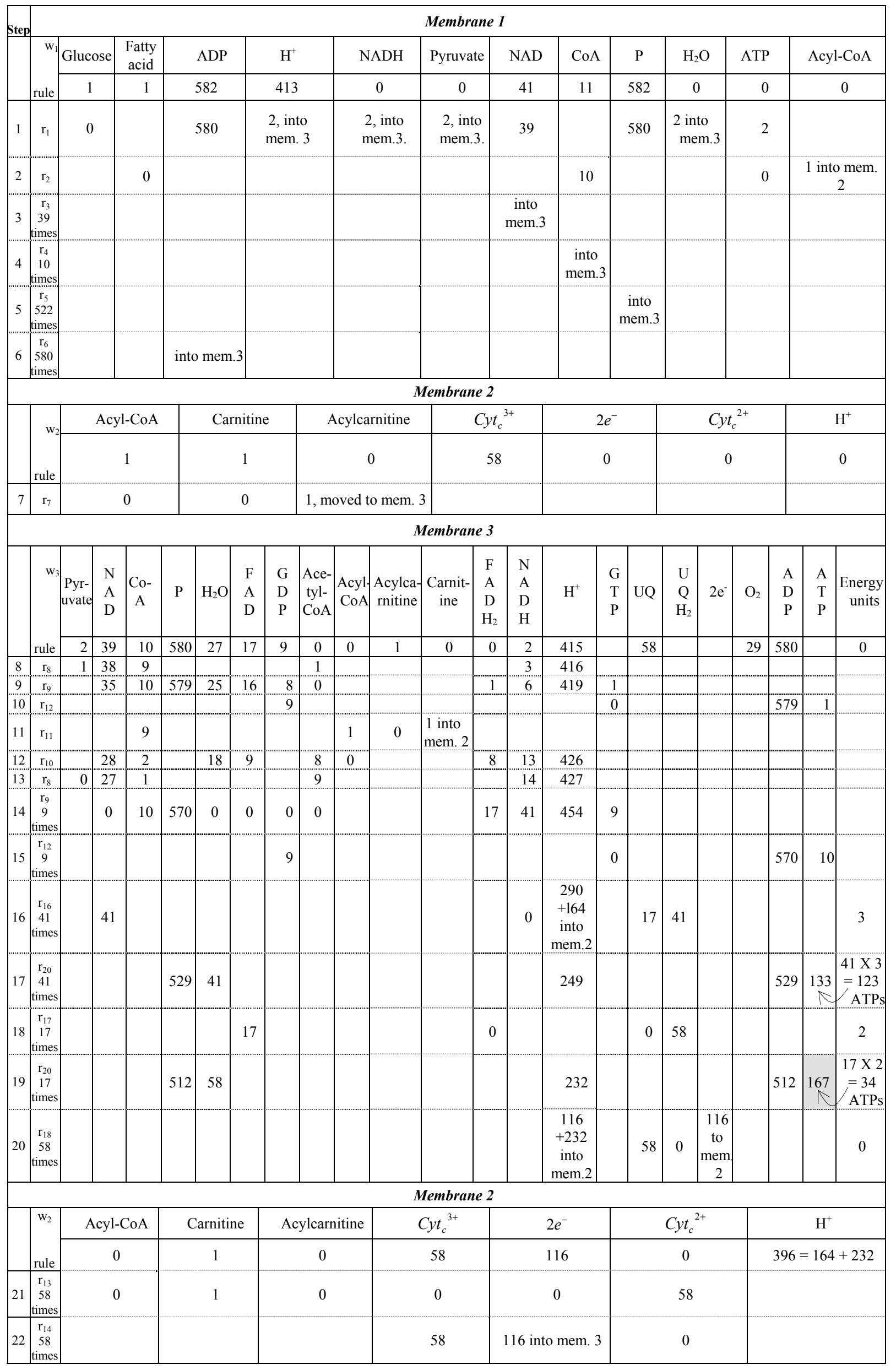


TABLE III (CONTINUED): PHASES OF EXPERIMENT 1

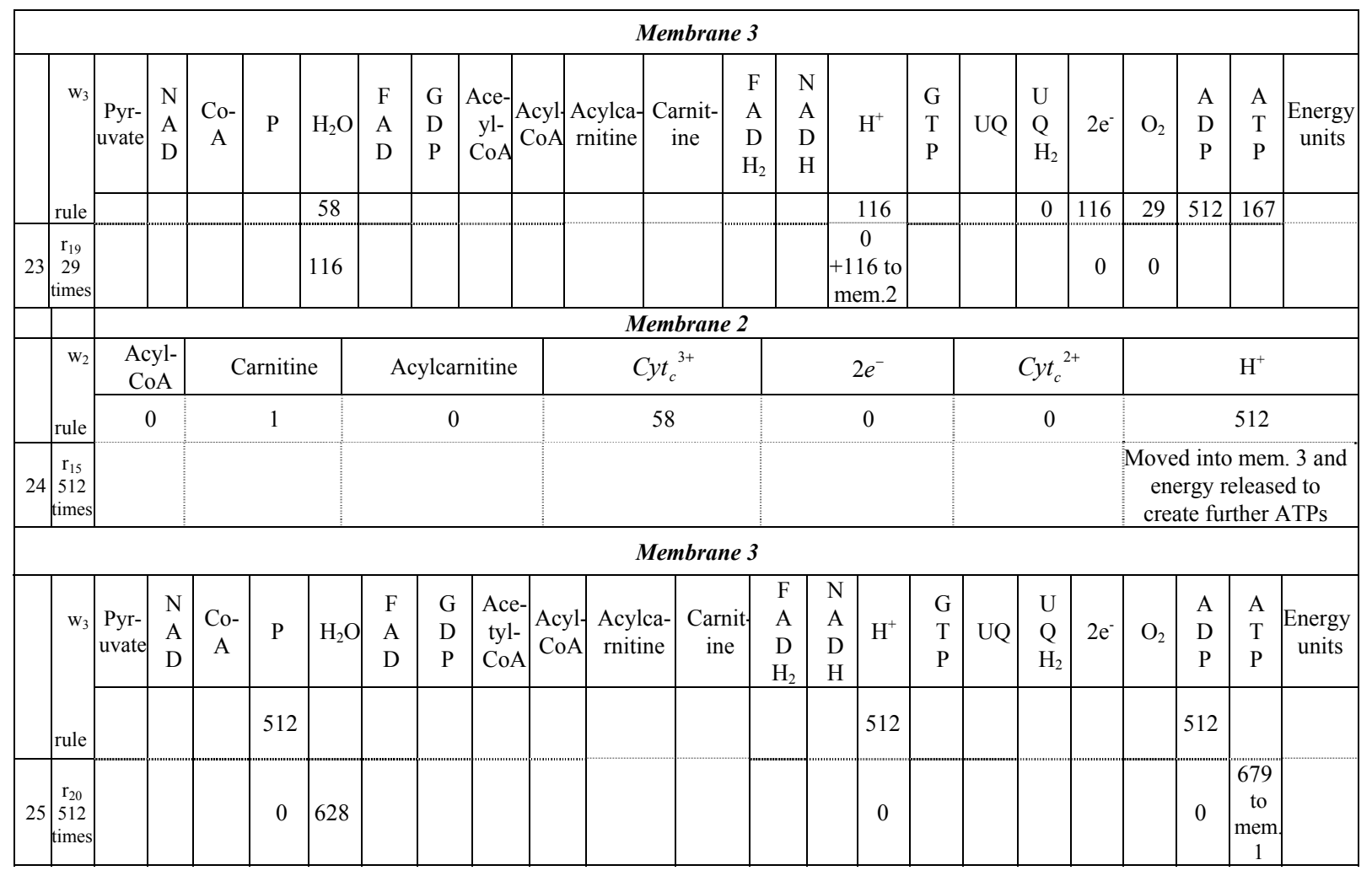

\section{B. Results}

Given enough number of molecules required for complete metabolism of one molecule of glucose and one molecule of fatty acid, the system produces $167 \mathrm{ATP}_{\mathrm{s}}$ from NADH and $\mathrm{FADH}_{2}$ passing their electrons. It is shaded in step 19 of table III. This result is correct and proved by references [1],[13]. When the electron transport chain is complete and there are enough molecules of $\mathrm{H}^{+}, \mathrm{P}$ and ATP, there are 512 extra ATPs produced. Notice that the number of $\mathrm{H}^{+}$translocated at each side of the mitochondrial inner membrane is controversial; the number indicates is consensus [1].

An important feature of $\mathrm{P}$ systems is the non-determinism of choosing rules. In table III, the order of execution of steps 1 and 2 could have alternated if we considered 2 ATPs in the input. Steps 16 and 18 could have been executed consecutively then steps 17 and 19. It is important to realize that if we enter less number of NAD molecules, 15 for instance, and the other inputs are the same as in table II, the output will not be the same when we run the simulator several times. In case of glucose metabolism running first, it will consume ten molecules of NAD ( $r_{1}$ once, $r_{8}$ twice and $r_{9}$ twice). At the same time of applying $\left(r_{1}\right)$, the fatty acid will be activated in the plasma membrane $\left(\mathrm{r}_{2}\right)$ consuming the 2 ATP molecules produced by glycolysis, Acyl-carnitine will be produced in the mitochondrial intermembrane space $\left(\mathrm{r}_{7}\right)$, transported into the inner mitochondrial membrane to produce Acyl-CoA and then there will not be enough NAD molecules to transform Acyl-CoA into Acetyl-CoA. That is, only 36 ATPs will be produced from the glucose molecule (steps $1,2,3$ and 4 in table I). If we consider fatty acid metabolism running first $\left(\mathrm{r}_{2}\right)$-given 2 input ATPs and 15 NAD molecules- then two molecules of NAD will be used by glycolysis $\left(r_{1}\right)$ because fatty acid activation does not need any
NAD molecules in the plasma membrane, then, in the mitochondrial inner membrane, the Acyl-CoA conversion to Acetyl-CoA will consume another seven NAD molecules $\left(r_{10}\right)$. The remaining six NAD molecules may be all used by Kerb's cycle ( $r_{9}$ twice) producing total number of 65 ATPs (steps 1,3,4 and 5 in table I), or the pyruvate conversion can use two NAD molecules and leaves four molecules to Kerb's cycle which will use three of them, and this will produce 59 ATPs (steps 1,2,3,5 and 1/2× step 4 in table I). Of course we can consider the use of those six NAD molecules alternating pyruvate conversion and Kerb's cycle. Because of the above example, the output of the simulator shows the complete path of the steps it executed. This path is used to verify the output of the system. Given enough number of input molecules or not, the simulator runs and produces the expected number of ATPs correctly according to the path it took.

\section{CONCLUSION}

$P$ systems can be used to represent the biological activities of cells. This paper is intended as a representation of a $\mathrm{P}$ simulator of the cellular metabolism of glucose and fatty acid concentrating on the functions of the mitochondrion. We first explained the definition of a $\mathrm{P}$ system, the evolution rules (transition rules), and the communication rules (carrier rules). Second, we introduced the current state of the research concerning metabolic P systems. Third, the basic important reactions within the cell and its mitochondrion were explained. Fourth, the construction of the proposed simulator is presented. Finally, the simulator is tested and the results are discussed. The simulator has successfully achieved the expected results and $\mathrm{P}$ systems proved its power. We think our work above contributes to the field of membrane computing. 
VII. NOMENCLATURE

TABLE IV: DEFINITIONS OF USED SYMBOLS

\begin{tabular}{|c|c|c|c|}
\hline ADP & $\begin{array}{l}\text { Adenosine } \\
\text { diphosphate }\end{array}$ & Co-A & $\begin{array}{l}\text { Coenzyme- } \\
\text { A }\end{array}$ \\
\hline ATP & $\begin{array}{l}\text { Adenosine } \\
\text { triphosphate }\end{array}$ & $\begin{array}{c}\text { Acyl- } \\
\text { CoA }\end{array}$ & \begin{tabular}{|l} 
Acyl- \\
Coenzyme- \\
A \\
\end{tabular} \\
\hline NAD & $\begin{array}{l}\text { Nicotinamide } \\
\text { adenine dinucleotide }\end{array}$ & $\mathrm{H}_{2} \mathrm{O}$ & Water \\
\hline FAD & $\begin{array}{l}\text { Flavin adenine } \\
\text { dinucleotide }\end{array}$ & GTP & $\begin{array}{l}\text { Guanosine } \\
\text { triphosphate }\end{array}$ \\
\hline GDP & $\begin{array}{l}\text { Guanosine } \\
\text { diphosphate }\end{array}$ & pyruvate & Pyruvic acid \\
\hline $\mathbf{P}$ & Phosphoric acid & $\mathrm{Cyt}_{\mathrm{c}}$ & $\begin{array}{l}\text { Cytochrome- } \\
\text { c }\end{array}$ \\
\hline $2 e^{-}$ & Pair of electrons & $\mathrm{Cyt}_{\mathrm{c}}{ }^{2+}$ & Oxidized $C y t_{c}$ \\
\hline $\mathrm{O}_{2}$ & Oxygen & FADH $_{2}$ & Reduced FAD \\
\hline $\begin{array}{c}\text { Acetyl- } \\
\text { CoA }\end{array}$ & $\begin{array}{l}\text { Acetyl } \\
\text { Coenzyme A }\end{array}$ & UQ & ubiquinone \\
\hline $\mathrm{Co}_{2}$ & Carbon dioxide & $\mathrm{Cyt}_{\mathrm{c}}{ }^{3+}$ & Reduced $C y t_{c}$ \\
\hline $\mathbf{H}^{+}$ & Hydrogen or proton & NADH & Reduced NAD \\
\hline $\mathbf{U Q H}_{2}$ & $\begin{array}{l}\text { Ubiquinol or reduced } \\
\text { UQ }\end{array}$ & \# & Number of \\
\hline
\end{tabular}

\section{REFERENCES}

[1] Karb, Gerald. (2004). Cell and molecular biology: Concepts and eExperiments. (Fifth edition). John Wiley and Sons Inc.
[2] Păun, Gh. (2002). Membrane computing. An introduction. Springer.

[3] Păun, Gh. (2000). Computing with membranes. Journal of Computer and System Sciences, 61(1):108-143.

[4] Păun, Gh. (2005). Membrane computing: Main ideas, basic results, applications. Retrieved on July $29^{\text {th }} 2008$ from www.dp.univer.it

[5] Păun, Gh.(2004). The $12^{\text {th }}$ Estonian Winter School in Computer Science (EWSCS). Introduction to membrane computing. Retrieved on July $1^{\text {st }} 2010$ from http://cs.ioc.ee/yik/schools/win2007/paun/

[6] Ioan I. Adrelean, Daneila Besozzi, Corrado Manara. (2004) Aerobic respiration is a bio-logic circuit containing molecular logic gates. Retrieved on June $23^{\text {rd }} \quad 2009$ from http://ppage.psystems.eu/index.php/Procwme5

[7] The MetaPlab Virtual Laboratory. Retrieved on October $1^{\text {st }} 2010$ from http://mplab.scienze.univr.it/index.html

[8] University of Sheffield. Retrieved on October $14^{\text {th }} 2010$ from http://www.dcs.shef.ac.uk/ marian/PSimulatorWeb/PSystemMF.htm

[9] University of Turento Centre for Computational and Systems Biology. $\begin{array}{lllll}\text { Retrieved on } & \text { October } & 14^{\text {th }} & 2010 & \text { from }\end{array}$ http://www.cosbi.eu/Rpty_Soft.php

[10] The P System Webpage. Retrieved on October $14^{\text {th }} 2010$ from http://ppage.psystems.eu

[11] Web page of wiley media retrieved on October $17^{\text {th }} 2010$ from http://media.wiley.com/Lux/36/8536.nfg001.jpg

[12] Web page of the mitochondrial disorder information. Retrieved on $\begin{array}{llll}\text { October } & 17^{\text {th }} & 2010 & \text { from }\end{array}$ http://www.mitochondrial-disorder-information.com/

[13] Norman Robert I., Lodwick David. (1999). Medical cell biology made memorable. Churchill Livingstone.

[14] The Medical Biochemistry Page. Retrieved on October $14^{\text {th }} 2010$ from $\mathrm{http}: / /$ themedicalbiochemistrypage.org

[15] Brookes, S.J. The Leeds Dental Institute, University of Leeds, UK. retrieved on June $18^{\text {th }} \quad 2010$ from http://www.dentistry.leeds.ac.uk/biochem/lecture/faox/faox.htm 